\title{
Inserção de um robô humanoide no Ensino de Objetos Geométricos 2D sobrepostos
}

\author{
Adam H. Moreira Pinto ${ }^{1}$, Lucas Orlandi de Oliveira ${ }^{1}$, Alcides X. Benicasa ${ }^{2}$, \\ Renata C. Geromel Meneghetti ${ }^{1}$, Roseli Ap. Francelin Romero ${ }^{1}$ \\ ${ }^{1}$ Instituto de Ciências Matemáticas e de Computação, Universidade de São Paulo, \\ São Carlos, São Paulo, Brasil. \\ ${ }^{2}$ Departamento de Sistemas de Informação, Universidade Federal de Sergipe, \\ Itabaiana, Sergipe, Brasil
}

[adam, lucas.orlandi.o]@gmail.com, alcides@ufs.br, [rcgm,rafrance]@icmc.usp.br

\begin{abstract}
Robotics, introduced into educational environments, can be an interesting alternative to explore theoretical concepts covered in class, faciliting learning and engaging the student's interest.In this paper, a computational system capable of detect objects was incorporated into the robot NAO, so that can interact with students, recognizing geometric shapes with overlap. The system consists of two models of neural networks and was evaluated through a sequence of didatic activities presented to students of the 5th year, aiming to encourage them. The robot operates autonomously, recognizing and counting the different objects in the image. The results show that the children felt very motivated and engaged to fulfill the tasks.
\end{abstract}

\begin{abstract}
Resumo. A robótica, inserida em ambientes educacionais, é uma alternativa interessante para explorar conceitos teóricos abordados em sala de aula, facilitando o aprendizado e cativando o interesse dos alunos.Neste artigo, um sistema computacional capaz de detectar objetos foi incorporado ao robô NAO para que o mesmo possa interagir com alunos, reconhecendo figuras geométricas com sobreposição. O sistema é constituído por dois modelos de Redes Neurais e foi avaliado por meio de uma sequência de atividades didáticas apresentadas a alunos do $5^{\circ}$ ano, visando estimulá-los. O robô atua autônomamente, reconhecendo e contando os diferentes objetos na imagem. Os resultados apresentados mostram que as crianças se sentiram muito motivadas para cumprir as tarefas.
\end{abstract}

\section{Introdução}

Atualmente, o uso da tecnologia no cotidiano das pessoas tem crescido a cada dia, podendo trazer benefícios inegáveis, em especial no âmbito educacional. Em linhas gerais, o objetivo da Inteligência Artificial é dar forma concreta às idéias, que antes pareciam abstratas, sobre o pensamento do homem [Papert 1985].

Segundo [Oliveira 2007], a Robótica apresenta-se como um importante recurso tecnológico, surgindo no processo de Ensino e Aprendizagem como um instrumento que possibilita a exploração dos diversos temas do currículo escolar. A forma natural como se dá a integração de conhecimentos de diversas áreas é um dos fatores mais relevantes associados à Robótica Educacional, visto que esta se desenvolveu com a pers- 
pectiva de aproximação às soluções de problemas das mais distintas áreas, como a Matemática, as Ciências Naturais e Experimentais, a Tecnologia e Ciências da Informação e da Comunicação.

Ainda segundo esse autor, os recursos tecnológicos, em especial a Robótica, como ferramenta pedagógica podem permitir ao professor demonstrar (de forma prática) aos alunos muitos dos conceitos teóricos, por vezes de difícil compreensão, motivando-os a observar, abstrair e inventar. Outra vantagem seria proporcionar aos alunos o desenvolvimento de capacidades de estruturação, de investigações e resolução de problemas, contribuindo para a formação de pessoas capazes de desenvolver novas habilidades, novos conceitos e responderem eficientemente aos aspectos em mudança no mundo que as rodeia.

Os ambientes de aprendizagem, por sua vez, contribuem com experiências para o desenvolvimento da criatividade e do pensamento dos alunos, estes: (i) constroem estratégias para a resolução de problemas e simulam o método científico, formulando hipóteses, implementando, testando e observando; (ii) fazem as devidas alterações sobre a solução acerca do significado dos objetos que manipulam; (iii) interiorizam conceitos tecnológicos, como por exemplo, estratégias de programação, de controle e de sincronização de processos; (iv) realizam estimações e medições; (v) adquirem e relacionam os conceitos de forma; (vi) partilham as suas criações com a comunidade escolar, principalmente os seus colegas, onde se questionam, enriquecem, valorizam e desenvolvem o sentido crítico, procedendo a um importante intercâmbio de experiências que contribuem para a aprendizagem através da análise e crítica construtiva; e, por fim, (vii) desenvolvem a autoestima [Oliveira 2007].

Ademais, dentro do contexto de aprendizagem significativa de [Ausubel 1982], acredita-se que a Robótica possa ser utilizada para auxiliar a construção de significados de conceitos no processo de Ensino e Aprendizagem de Matemática, pois esta oportuniza a reflexão sobre essa prática e o aprimoramento do conhecimento elaborado pelo aluno.

Este artigo tem como objetivo apresentar uma possibilidade de utilização da Robótica no processo de Ensino e Aprendizagem de Matemática na Educação Básica, visando o ensino de figuras geométrica planas, por meio do auxílio de um robô humanoide, denominado NAO. Um sistema computacional capaz de detecção de objetos salientes em uma cena e classificação de objetos, proposto em [Benicasa et al. 2013], foi incorporado ao sistema de controle do humanoide NAO. Uma sequencia de atividades didáticas foram por nós elaboradas e aplicadas, que visam permitir que o aluno construa um raciocínio matemático para solucionar o problema apresentado, contando com o auxílio do humanoide em determinadas fases da elaboração da solução do problema. As atividades permitem explorar o reconhecimento de figuras geométricas planas, tais como: quadrado, triângulo, retângulo, paralelogramo e trapézio e foram aplicadas a alunos do $5^{\circ}$ ano do Ensino Fundamental I.

Este artigo está organizado como se segue: Na seção 2 é apresentada a metodologia utilizada para que o robô detecte os objetos mais salientes e os classifique dentre os objetos que são do seu conhecimento. Na seção 3 são descritos os experimentos que foram realizados com os alunos. Os resultados desses experimentos são discutidos na seção 4 e a conclusão deste trabalho e trabalhos futuros, são apresentados na seção 5. 


\section{Metodologia}

\subsection{Robo NAO}

O robô NAO é um humanoide de cerca de $60 \mathrm{~cm}$ de altura, com massa em torno de $5 \mathrm{Kg}$, assemelha-se ao tamanho de uma criança e possui 25 graus de liberdade cujos elementos chave são os motores elétricos e atuadores; rede de sensores, incluindo duas câmeras, quatro microfones, sonar telemétrico, dois emissores e receptores IR; uma placa de inércia, nove sensores táteis e oito sensores de pressão; vários dispositivos de comunicação, incluindo o sintetizador de voz, luzes LED, e dois alto-falantes de alta fidelidade; ATOM 1,6 $\mathrm{GHz}$ Intel (localizado na cabeça) que executa um kernel do Linux e suporta middleware da Aldebaran (Naoqi), em segundo lugar CPU (localizada no tronco); bateria 27,6 W-h que fornece ao NAO em torno de 1,5 horas de autonomia, dependendo do uso. Desenvolvido por uma empresa francesa, Aldebaran Robotics, este robô passou a possuir maior expressão junto à comunidade robótica por ter sido eleito para substituir o extinto robô Aibo da Sony Corporation em uma categoria da competição mundial de futebol de robôs, RoboCup Standard Platform League .

O robô tem sido utilizado em mais de 550 universidades e laboratórios de pesquisa espalhados pelo mundo. Robótica, Inteligência Artificial, Ciência de Computação divergindo para Sociologia e Cuidados Médicos são algumas das áreas de pesquisa onde esse robô tem sido utilizado.

Esta arquitetura permite a interação com outros robôs ou seres humanos por meio de distintas formas, as quais podem ocorrer pela fala, localização sonora, padrão visual e detecção de corpo, detecção de faces, detecção de obstáculos e efeitos visuais em LEDs que possui. O robô possui um sistema multimídia com dois alto-falantes (localizados nas laterais da cabeça), quatro microfones, duas câmeras digitais (dois orifícios, um na "testa", outro na "boca"), sensores táteis na cabeça e mãos, bumpers nos pés, sonares no seu torço, etc. A Figura 1 é mostrado a versão mais atual do robô NAO.

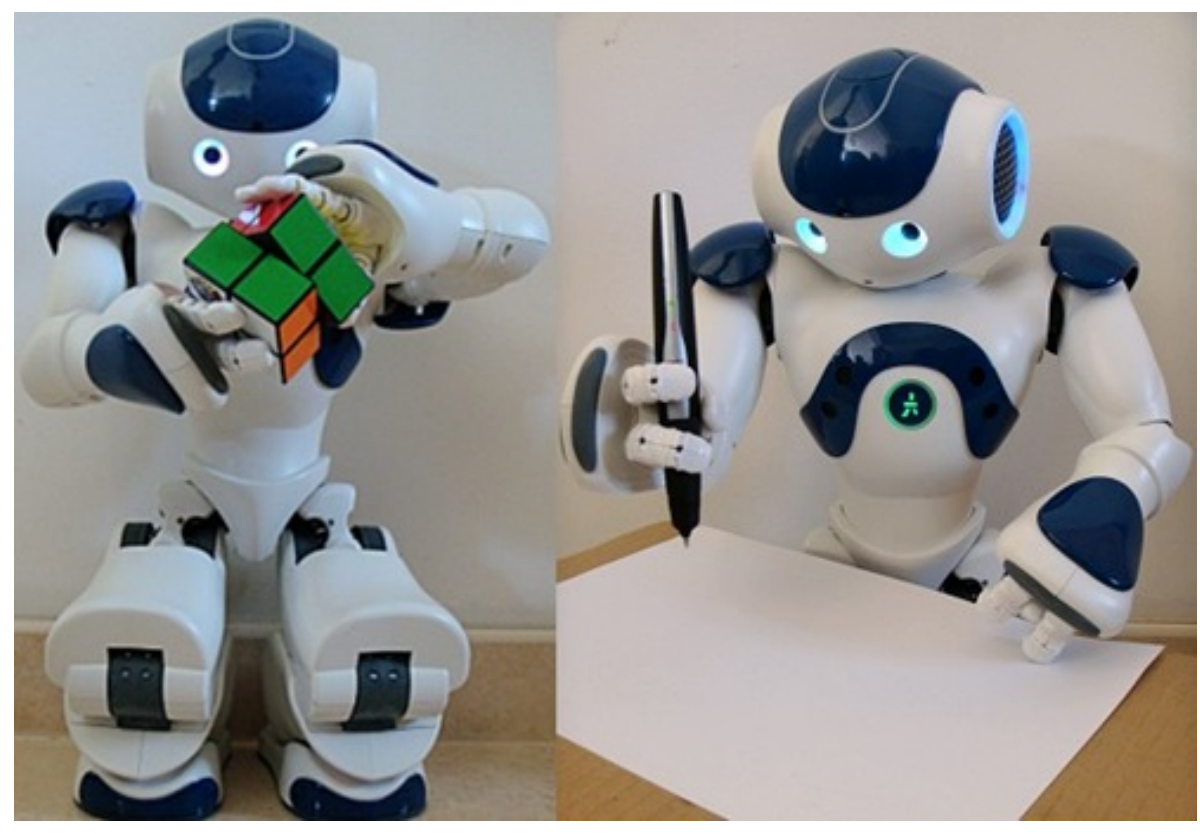

Figura 1. Versão mais recente do robô Nao [Aldebaran 2014] 


\subsection{Sistema de Visão}

O sistema proposto é constituído dos seguintes módulos: o módulo de extração de características visuais, uma rede neural pertencente a $3^{a}$ geração, LEGION (Locally Excitatory, Globally Inhibitory Oscillatory Network - Rede Osciladora Localmente Excitatória, Globalmente Inibitória), uma Rede Neural MLP (MultiLayer Perceptron - Rede Perceptron Multicamadas) [Halkin 2001] que é um classificador de alto nível muito conhecido para reconhecimento de objetos.

O primeiro módulo é responsável por extrair características visuais inicias da cena, retirando informações importantes de orientação, cor e intensidade. Os resultados dessa análise são os dados de entrada da rede LEGION, seguindo o algoritmo proposto em [Wang and Terman 1997].

A segmentação na rede LEGION segue a ideia de que cada segmento contem pelo menos um oscilador (um neurônio), que é chamado de líder, que está no centro de uma grande região homogênea. O modelo proposto em [Benicasa et al. 2013], que está sendo utilizado no presente trabalho, utiliza tanto modulação bottom-up quanto a modulação top-down. Enquanto as características visuais retiradas no primeiro momento (constrastes de cor e orientação) são o sinal da modulação bottom-up, as informações memorizadas previamente sobre as características dos objetos (através da rede MLP) guia o processo de seleção top-down.

A rede MLP é um classificador que compara uma imagem atual com dados obtidos em treinamento anterior. Durante o treinamento, figuras geométricas foram apresentadas isoladamente para a rede que, através de um algoritmo de retropropagação de erro (BackPropagation) [Halkin 2001], consegue convergir para um indice de certeza, no qual novas imagens, nunca antes mostradas à rede, são rotuladas de forma correta. A cada pulso da rede LEGION, uma região homogênea é salientada, desconsiderando-se o resto da imagem. Essa região é enviada para a rede MLP, que rotula se aquela região é conhecida (quadrado, triângulo, retângulo, etc) ou não. Uma vez que a MLP conseguiu classificar aquela imagem salientada como uma figura geométrica, ela é contabilizada. Ao final da classificação, este processo é repetido novamente. A Figura 2 apresenta os passos da segmentação da imagem e toda a equalização deste modelo pode ser encontrado em [Pinto et al. 2014].

Este sistema computacional foi incorporado a um robô humanoide NAO. Este robô vem sendo usado com sucesso em várias atividades que envolvem interação homem/robô. Vários trabalhos têm sido realizados em distintos ramos da Ciência, utilizando o robô humanoide NAO.

Suay e Chernova [Suay and Chernova 2011] utilizaram o sensor Kinect junto com um humanoide NAO para permitir que o robô imitasse o movimento dos braços do usuário, tivesse seu caminhar ordenado e o olhar do robô fosse direcionado pela posição da mão direita para ordem de deslocamento. Estas funcionalidades foram obtidas pelo estabelecimento de alguns modos de controle com relação à posição de alguns membros do corpo do usuário.

Veltrop [Veltrop 2012] fez uso da fusão de vários sensores para teleoperar um humanoide NAO. Para tal, utilizou o sensor Kinect para estimação das configurações espaciais do corpo do usuário; um controle Wiimote para melhor estimação das configurações 


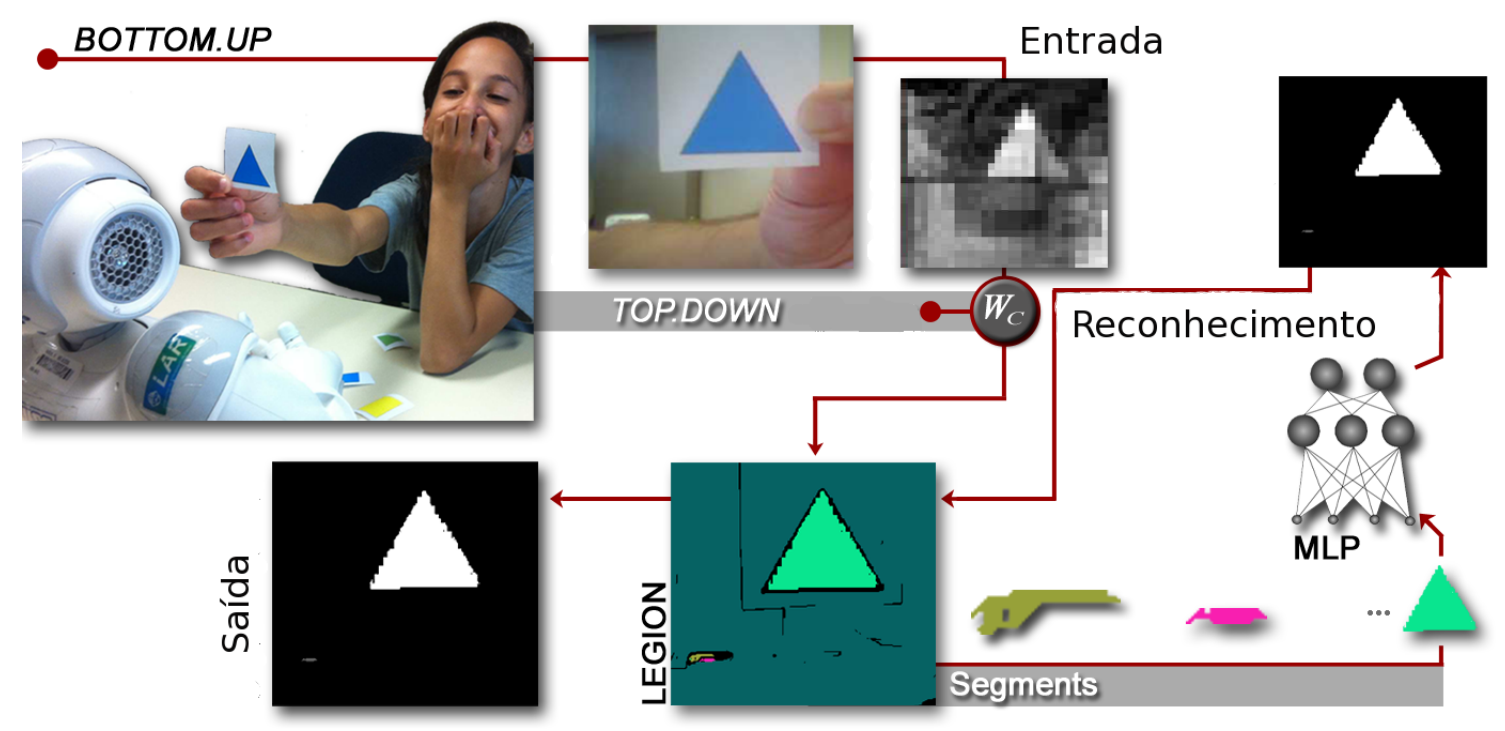

Figura 2. A arquitetura da segmentação baseada em objetos

da mão/punho e ativação de determinados comportamentos no robô; uma esteira para permitir o robô caminhar conforme o caminhar do usuário na esteira evitando, assim, que o mesmo saísse do campo de visão do Kinect; e um head-mounted display servindo como a visão do robô no usuário.

Koenemann e Bennewitz [Koenemann and Bennewitz 2012] utilizaram uma vestimenta de sensores inerciais no corpo de um usuário a fim de capturar as configurações das junções de seu corpo e mapeá-las para as junções do robô em tempo-real. Também, foi desenvolvido um módulo de balanço que permitisse o robô se comportar de forma estável durante a imitação. O robô humanoide desempenhou a imitação adequadamente durante a interação, permitindo também a estável imitação do movimento de ambas as pernas sem cair no chão.

Na Figura 3 podem ser vistos a teleoperação realizadas pelos trabalhos mencionados.
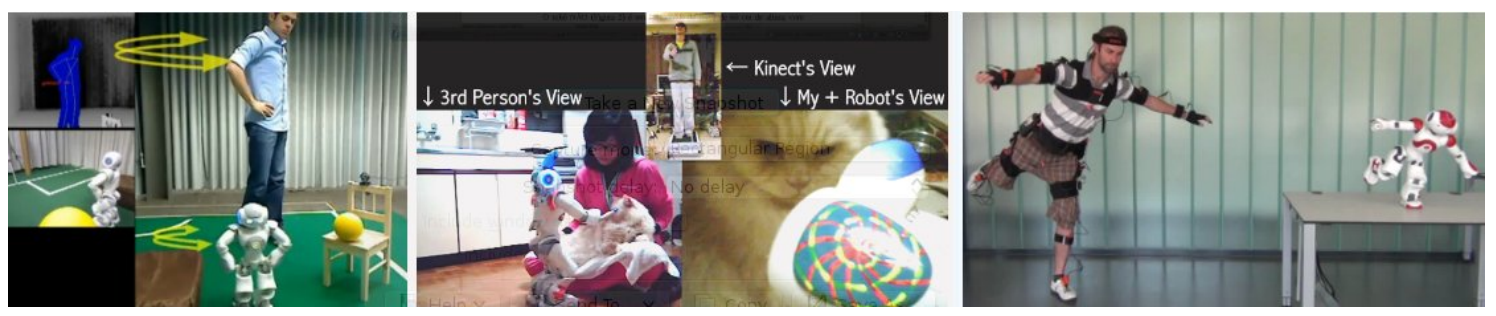

Figura 3. Interação humano-robô por meio de teleoperação

Zuher e Romero [Zuher and Romero 2012] usaram técnicas simples de matemática para tornar o humanóide NAO capaz de receber comandos, através da interação com o Kinect, em tempo real para caminhar, manipular objetos com suas mãos e realizar alguns comportamentos pré-definidos (sentar, se levantar e acenar com a mão) além de imitar os movimentos de braços e pernas de uma pessoa.

Em um estudo de interação social feito por [Tapus et al. 2012], um experimento 
com quatro crianças foi proposto, onde a interação com o robô NAO e com um humano era comparada. Duas dessas crianças não mostraram qualquer efeito com a presença do robô, porém as outras duas prestaram mais atenção ao robô do que ao humano, sendo que uma delas mostrou uma grande interação com o robô. Já em outro teste, feito por [Csala et al. 2012], crianças que são forçadas a ficar em pequenas caixas estéreis de 2x3 metros devido a uma cirurgia tiveram respostas bem positivas ao robô NAO, que as animava e convidava para fazer alguns exercícios.

Kimberlee et al. [Kimberlee et al. 2013] investigou o uso de robôs para aumentar a comunicação e a atenção de adolecentes com transtorno de espectro autista. Para tal, adolecentes com autismo eram colocados para jogar juntamente com três outros adolecentes com outros distúrbios, recrutados de escolas de pessoas com necessidades especiais. Os testes foram feitos em três dias, não consectivos, onde os adolecentes autistas jogavam de três diferentes formas: a) com um robô humanóide, b) com uma Smart Board e c) com cartas. Apesar de apresentarem comportamentos individualistas nos três modos, o comportamento repetitivo foi diminuído quando utilizado tanto o robô como a Smart Board, mostrando que é possível o uso de robôs para ajudar no aprendizado. Além disso, a pesquisa do estado-da-arte feita em [Shamsuddin et al. 2012] mostra que o uso dos robôs vêm sendo testado por muitos pesquisadores, com bons resultados.

Pinto et al. [Pinto et al. 2014] utilizaram o robô humanoide NAO para o ensino de figuras geométricas simples, sem sobreposição, tais como, triangulo, quadrado e retângulo. A abordagem do experimento consistia em um jogo de perguntas, no qual o robô dava dicas sobre uma figura geométrica, tais como quantidade de lados, fórmula da área, fórmula do perímetro, que a criança deveria apresentar para ele. Após ouvir a dica do robô, o aluno escolhia uma das diversas figuras presentes na mesa e o robô indicava se a resposta estava correta. Caso contrário, o humanóide NAO dava uma nova dica e, ao final, sempre explicava e dava dicas sobre a figura que deveria ser reconhecida.

\section{Experimentos Realizados}

Os experimentos foram realizados com um grupo constituído de 30 alunos do $5^{\circ}$ ano (série final do primário) de uma escola da rede publica de ensino de São Carlos, com idades entre 13 e 14 anos. As atividades foram divididas em três partes, sendo duas de aplicação de questionários e outra com a utilização do robô NAO.

Inicialmente, as crianças foram levadas a uma sala de aula, onde responderam a um questionário pré-atividade, que visava colher informações sobre o conhecimento delas a respeito de figuras geométricas planas. Em seguida, uma criança por vez foi levada até outra sala, para interagir com o robô NAO.

A atividade com o robô NAO foi realizada com cada criança individualmente. Durante essa atividade foram apresentadas à criança duas imagens (vistas nas Figuras 4 e 5) baseadas no Tangram ${ }^{1}$, que continham figuras geométricas planas sobrepostas. Após mostrar a imagem ao robô, para que ele pudesse fazer o reconhecimento das figuras geométricas presentes nela, o aluno deveria identificar e contar todas as figuras

\footnotetext{
${ }^{1}$ Tangram é um quebra-cabeça chinês formado por 7 peças ( 5 triângulos, 1 quadrado e 1 paralelogramo). Com essas peças é possível montar mais de 1700 figuras. O tangram é utilizado pelos professores de matemática como instrumento facilitador da compreensão das formas geométricas.
} 
geométricas presentes na imagem e, após isto, falar ao NAO quantas figuras foram identificadas.

Graças ao sistema computacional proposto em [Benicasa et al. 2013], o robô consegue salientar, em cada pulso da rede, uma diferente figura geométrica presente na imagem. Essa figura detectada foi classificada, por meio rede multicamada, em uma das figuras previamente ensinadas ao robô (como triângulo, retângulo, quadrado, etc). Uma vez que a imagem salientada correspondesse à alguma figura reconhecida, o robô contabilizava aquela figura e continuava o reconhecimento, de forma totalmente autônoma. Por outro lado, o aluno deveria fazer o mesmo: encontrar todas as figuras geométricas presentes naquela imagem, classificá-las e contá-las. Caso a criança errasse, o robô dava uma segunda chance, explicando que havia encontrado um número maior de figuras.

Ao concluir a atividade com o robô NAO, o aluno retornava à sala anterior, onde era submetido à aplicação de outro questionário. Dessa vez, o questionário exibia um retângulo e um quadrado, onde era pedido que a criança identificasse quadrados e triângulos dentro de cada uma das formas geométricas exibidas, respectivamente. Salienta-se que a figura utilizada no segundo questinário era diferente da primeira.

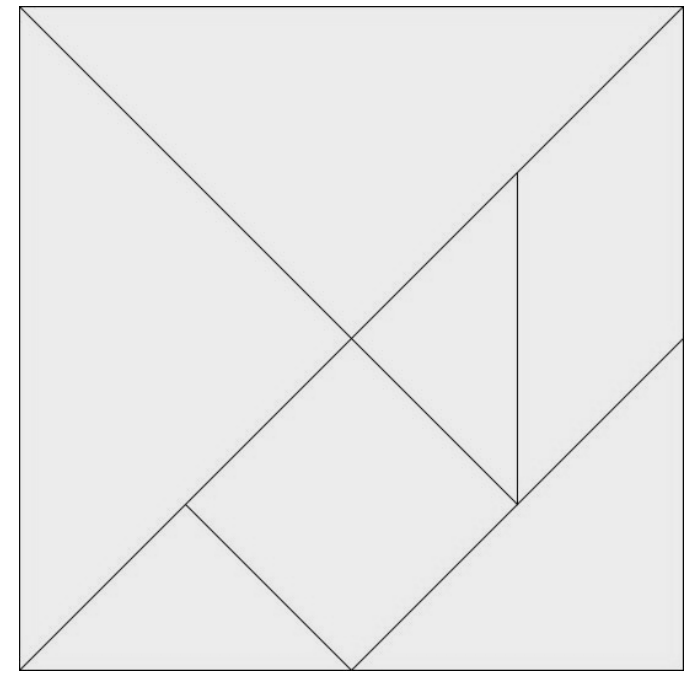

Figura 4. Primeira figura apresentada para os alunos

Para 10 desses alunos, entretanto, as atividades foram todas realizadas sem a presença do robô NAO, para poder ser comparado a atividade junto ao robô.

\section{Discussão dos Resultados}

Analisando os resultados do primeiro questionário aplicado, notamos que todos os alunos possuem conhecimento sobre as formas geométricas exibidas durante a atividade. Apesar disso, nenhum deles acertou o número de formas geométricas contidas na primeira imagem apresentada (Figura 4), pois não identificaram as formas geométricas constituídas da sobreposição de outras, como mostrado na Figura 6, considerando-se as 20 crianças que fizeram os testes com o robô. No caso dessa figura, todos os alunos responderam que viam sete figuras em um primeiro momento, se mostrando surpresos quando o robô respondia que havia encontrado mais figuras. 


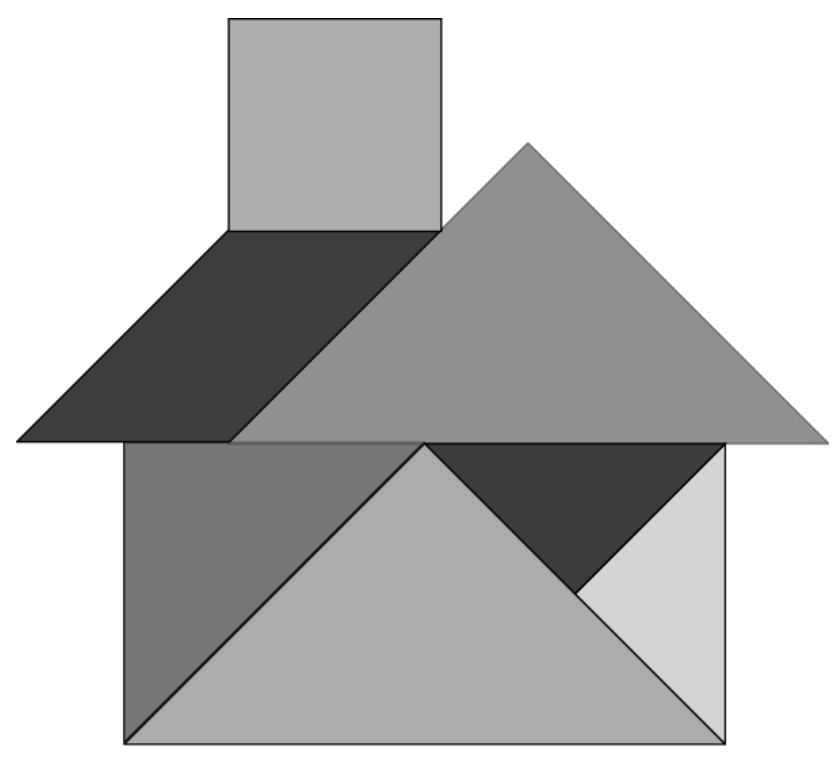

Figura 5. Segunda figura apresentada

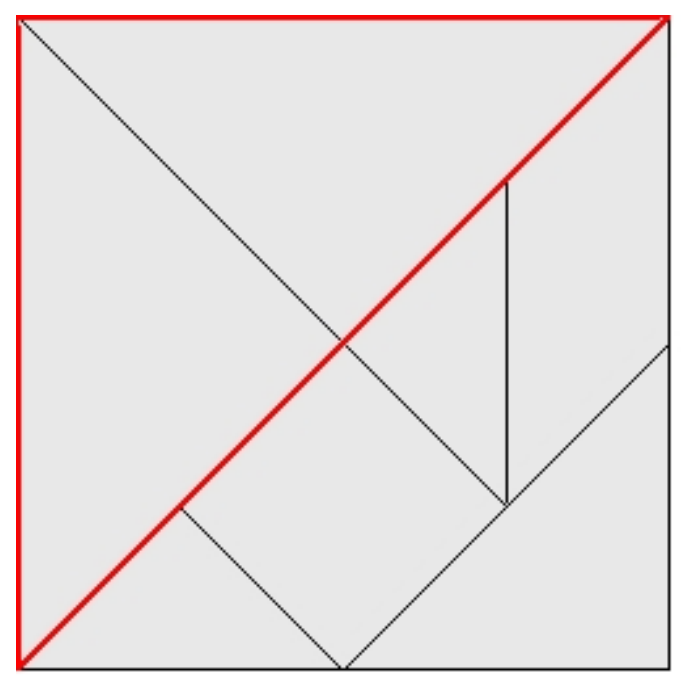

Figura 6. Exemplo da sobreposição de figuras geométricas

Pode ser observado que, ao receber uma nova chance, cada aluno se empenhou bastante e insistiu em encontrar todas as possíveis formas geométricas. Ainda na primeira imagem, apenas $25 \%$ (5) dos alunos conseguiram enxergar mais alguma figura escondida, porém nenhum deles encontrou todas as figuras que o robô encontrou (no caso, um total de 15). Os outros $75 \%$ dos alunos não conseguiram encontrar outras imagens e somente compreenderam o objetivo da atividade quando o robô indicou onde estavam todas figuras.

Finalizado o primeiro experimento, o aluno apresentava a segunda figura (Figura 5) para o robô. Uma vez que tinham entendido o primeiro jogo, todos os alunos relutaram em responder que viam novamente sete figuras. Apesar de todos conseguirem reconhecer mais figuras sobrepostas, apenas $15 \%$ (3) deles conseguiram encontrar todas as nove figuras reconhecidas pelo robô. 
A percepção das crianças em relação a figuras geométricas ocultas dentro de outras melhorou após as atividade com o robô. Isso foi notado ao realizarmos um contraste entre as respostas obtidas na primeira etapa da atividade com o NAO e as respostas do segundo questionário aplicado. Enquanto na primeira atividade nenhum aluno conseguiu identificar todas as figuras geométricas contidas na imagem, no questionário, apesar de identificarem números diferentes de quadrados e triângulos, $100 \%$ dos alunos conseguiram notar que haviam figuras ocultas dentro de outra.

$\mathrm{Na}$ figura do retângulo, onde era pedido para identificar e contar quantos quadrados ocultos haviam, alguns alunos conseguiram enxergar mais do que outros; enquanto a maioria (90\%) identificou apenas dois quadrados, um deles identificou oito, e outro destacou 32 quadrados.

Na figura do quadrado, onde as crianças deveriam identificar e contar triângulos, cinco alunos destacaram quatro triângulos, quatro destacaram dois triângulos, dois destacaram três e 19 crianças identificaram oito triângulos dentro do quadrado.

A atividade com as demais 10 crianças, que fizeram sem a presença do robô, teve resultados parecidos, porém nenhuma das crianças conseguiu encontrar todas as figuras escondidas em nenhuma das atividades. Isso pode ser explicado pela perda de interesse no jogo, uma vez que as atividades eram conduzidas por pessoas que não eram seus professores da escola. Os alunos logo chutavam a resposta e se empenharam muito menos, já que não tinha a competição com o robô.

\section{Conclusão e Trabalhos Futuros}

A análise dos experimentos mostrou que os alunos se sentem desafiados à realizarem as atividades quando estão diante do robô. O auxílio do humanoide foi uma motivação, uma vez que era novidade para as crianças, o que serviu para prender a atenção ao que estava sendo proposto. O robô NAO conseguiu reconhecer as figuras geométricas ocultas, seu diálogo foi claro e foi bem aceito por todos os alunos.

Em conversas após o término dos experimentos, as crianças declararam ter gostado muito das atividades e que gostariam de participar de novos experimentos. Todos os testes foram acompanhados por uma professora, que também aprovou a postura do robô. Apesar do pouco tempo que os alunos tiveram para interagir com o robô e de ser somente duas atividades diferentes, nota-se, pela análise dos resultados, que muitos alunos entenderam o objetivo das atividades e abstrairam o conceito que era esperado. Certamente, é necessário a realização de mais experimentos com um tempo maior dedicado a cada uma delas para se possa ter um parecer mais conclusivo.

Como trabalhos futuros, pretendemos passar a utilizar o Tangram como forma de ensinar as crianças a entender na prática conceitos de área. Pretendemos também, utilizando robôs, consolidar alguns conceitos de ângulos e trigonometria.

\section{Referências}

Aldebaran (2014). Disponível em: http://trends.directindustry.com/products/this-pintsized-robot-plays-soccer-but-youll-never-guess-what-else-it-can-do/.

Ausubel, D. P. (1982). A aprendizagem significativa: a teoria de david ausubel. São Paulo: Moraes. 
Benicasa, A., Quiles, M., Zhao, L., and Romero, R. (2013). Top-down biasing and modulation for object-based visual attention. In Lee, M., Hirose, A., Hou, Z.-G., and Kil, R., editors, Neural Information Processing, volume 8228 of Lecture Notes in Computer Science, pages 325-332. Springer Berlin Heidelberg.

Csala, E., Nemeth, G., and Zainko, C. (2012). Application of the nao humanoid robot in the treatment of marrow-transplanted children. International Conference on Cognitive Infocommunications (CogInfoCom), pages pp. 655-659.

Halkin, S. (2001). Artifical Neural Networks: Methods and Application. Bookman.

Kimberlee, J., King, M., Hellersteth, S., Wiren, A., and Mulligan, H. (2013). Feasibility of using a humanoid robot enhancing attention and social skills in adolescents with autism spectrum disorder. International Journal of Rehabilitation Research.

Koenemann, J. and Bennewitz, M. (2012). Whole-body imitation of human motions with a nao humanoid. presented at the Proceedings of the seventh annual ACM/IEEE international conference on Human-Robot Interaction, Boston, Massachusetts, USA.

Oliveira, R. (2007). Tecnologia na aula de matemática: Robótica na educação. Tese Departamento de Matemática e Engenharia, Universidade de Madeira, Minas Gerais, p.39-45.

Papert, S. M. (1985). Logo: Computadores e educação. São Paulo, Editora, Brasiliense.

Pinto, A. H. M., Benicasa, A. X., Oliveira, L. O., Meneguetti, R. C. G., and Romero, R. A. F. (2014). Attention based object recogniton applied to a humanoid robot. A ser publicado.

Shamsuddin, S., Yussof, H., Ismail, L., Hanapiah, F. A., Mohamed, S., Piah, H. A., and Zahari, N. I. (2012). Initial response of autistic children in human-robot interaction therapy with humanoid robot nao. International Colloquium on Signal Processing and its Applications, pages pp. 188-193.

Suay, H. B. and Chernova, S. (2011). Humanoid robot control using depth camera. presented at the Proceedings of the 6th international conference on Human-robot interaction, Lausanne, Switzerland.

Tapus, A., Peca, A., Aly, A., Pop, C., Jisa, L., Pintea, S., Rusu, A., and David, D. (2012). Childrens with autism social engagement in interaction with nao, an imitative robot: A series of single case experiments. John Benjamins Publishing Company, 13(3):315347.

Veltrop, T. (2012). Disponível em: http://taylor.veltrop.com/.

Wang, D. and Terman, D. (1997). Image segmentation based on oscillatory correlation. Neural Computation, 9:805-836.

Zuher, F. and Romero, R. A. F. (2012). Whole-body imitation and recognition of human motions through a humanoid robot. In: SBR/LARS - Simpósio Brasileiro de Robótica/Latin American Robotics Symposium, 2012, Fortaleza - CE. Anais do SBR, 2012. p. 190-195. 